\title{
Juventude, Mundo do Trabalho e Vulnerabilidade Social: $O$ Desemprego Juvenil no Brasil como uma Expressão da Condição de Subalternidade da Classe Trabalhadora ${ }^{1}$
}

\author{
Youth, World of Work and Social Vulnerability: \\ Youth Unemployment in Brazil as an Expression of \\ the Subalternity Condition of the Working Class
}

\author{
Silmara Carneiro e Silva \\ Pedro Henrique Galeto** \\ Rafaela Karoline Bastista ${ }^{* * *}$
}

\begin{abstract}
Resumo: Este trabalho tem como objeto de estudo o desemprego juvenil no Brasil enquanto uma expressão da condição de subalternidade dos grupos vulneráveis socialmente no âmbito da sociedade de classes. A partir desta compreensão, o presente trabalho visa analisar o desemprego juvenil na atualidade brasileira. Trata-se de uma pesquisa de natureza bibliográfica e documental, partindo de referencial gramsciano e de autores que discutem sobre juventude e o mundo do trabalho. Aborda, inicialmente, os conceitos de juventude, subalternidade e vulnerabilidade social buscando compreender as suas intersecções do mundo do trabalho, considerando a atualidade do capitalismo. Na sequência realiza uma análise sobre o desemprego como uma das expressões da condição histórica de subalternidade da classe trabalhadora na ordem do capital e como esta condição se expressa particularmente na vida de jovens vulneráveis socialmente no Brasil atual. Apresenta ainda neste item uma análise de dados quantitativos referente ao tema, a partir de fontes oficiais à luz dos conceitos trabalhados anteriormente. Compreende-se que o desemprego juvenil, enquanto uma expressão da situação de vulnerabilidade
\end{abstract}

\footnotetext{
${ }^{1}$ Uma versão preliminar deste texto foi apresentada no "III SIMPÓSIO INTERNACIONAL INTERDISCIPLINAR EM CIÊNCIAS SOCIAIS APLICADAS: Democracia e direitos humanos" realizado em Ponta Grossa- PR, entre 11 a 13 de setembro de 2019, sendo indicado pelo evento para compor este volume especial da Emancipação.

*Doutora em Serviço Social e Política Social pela Universidade Estadual de Londrina - UEL. Mestre em Ciências Sociais Aplicadas pela Universidade Estadual de Ponta Grossa - UEPG.Graduada em Serviço Social pela UEPG. Professora do Departamento de Serviço Social e do Programa de Pós-graduação em Ciências Sociais Aplicadas da UEPG. E-mail: scsilva@uepg.br.

** Mestrando em Ciências Sociais Aplicadas pela Universidade Estadual de Ponta Grossa - UEPG. Graduado em Psicologia pela Faculdade Sant'Anna. E-mail: pedrogaleto@gmail.com

${ }^{* * *}$ Graduada em Filosofia pela Faculdade Sant'Anna. Graduanda em Serviço Social pela Universidade Estadual de Ponta Grossa. Pesquisadora do Programa Voluntário de Iniciação Científica - PROVIC pela UEPG. E-mail.rafaelakarolinebatista@gmail.com.
} 
social da juventude brasileira no contexto atual do mundo do trabalho revela, particularmente, uma expressão da condição estrutural de subalternidade da classe trabalhadora no capitalismo contemporâneo.

Palavras-chave: Juventude; Subalternidade; Vulnerabilidade Social; Mundo do Trabalho; Desemprego Juvenil.

\begin{abstract}
This study aims to study youth unemployment in Brazil as an expression of the subaltern condition of socially vulnerable groups within the class society. From this understanding, the present work aims at analyzing the youth unemployment in the Brazilian reality. It is a research of bibliographical and documentary nature, starting from gramscian referential and authors that discuss about youth and the world of work. Initially, it approaches the concepts of youth, subalternity and social vulnerability, seeking to understand their intersections of the world of work, considering the actuality of capitalism. In the sequence, he analyzes unemployment as one of the expressions of the historical condition of subalternity of the working class in the order of capital and how this condition is expressed particularly in the lives of socially vulnerable young people in Brazil today. It also presents an analysis of quantitative data referring to the topic, from official sources in light of previously worked concepts. It is understood that youth unemployment, as an expression of the situation of social vulnerability of Brazilian youth in the current context of the world of work reveals, in particular, an expression of the structural condition of subalternity of the working class in contemporary capitalism.
\end{abstract}

Keywords: Youth; Subalternity; Social vulnerability; World of Work; Unemployment Juvenile.

Recebido em 20/01/2020. Aceito em 17/07/2020

\title{
Introdução
}

Desde a década de 70 o mercado de trabalho brasileiro vem sofrendo desaceleração, o que tem como consequência a precarização da condição de vida dos trabalhadores e o aumento da informalidade. (MATOS; PEREIRA, 2016). Dal Bello (2004) dispõe que a estabilidade nas relações de trabalho torna-se algo ausente na sociedade contemporânea, que sofre os impactos das flutuações do mercado. Contudo, o padrão societário não segue a mesma frequência. Neste, as aparências regidas pela "ostentação" se tornam cada vez mais midiatizadas, tendo como foco, principalmente, os jovens. Esse padrão midiático faz com que objetos, assim como o uso de drogas e situações de expressão de violência se tornem símbolos de poder (DAL BELLO, 2004). Conforme visto inicialmente a estabilidade de trabalho no meio formal, sobretudo através do vínculo empregatício, não é mais uma constante na vida do indivíduo, que se vê desprovido da proteção pela vida do trabalho e terá como necessidade a busca de outras formas de realização e proteção, considerando a situação de vulnerabilidade a que é exposto, no atual contexto. Diante deste 
quadro contextual, os jovens brasileiros se tornam grupo focal, por conta de sua suscetibilidade a esses fatores. (DAYHELL, 2003). Segundo o Estatuto da Juventude, são considerados jovens “as pessoas com idade entre 15 (quinze) e 29 (vinte e nove) anos de idade” (LEI 12.852/13, Art. 1요 § 1).

Dado tais pressupostos, este trabalho tem por objetivo analisar o desemprego juvenil no Brasil enquanto uma expressão da condição de subalternidade dos grupos vulneráveis socialmente no âmbito da sociedade de classes.

A presente pesquisa é qualitativa, com a utilização de dados quantitativos oriundos de fontes oficiais como suporte das análises. Apresenta uma revisão de literatura, partindo do referencial teórico gramsciano e pautada ainda em obras de autores que abordam temáticas afetas à pesquisa: juventude, vulnerabilidade social, subalternidade e mundo do trabalho no capitalismo contemporâneo e no Brasil. Para tanto, recorre-se a autores marxistas e marxistas gramscianos, para análise do conceito de subalternidade e sobre as questões afetas ao mundo do trabalho e em autores que discutem sobre o tema da vulnerabilidade social e juventude. Assim, o primeiro item do trabalho aborda os conceitos de juventude, subalternidade e vulnerabilidade social buscando compreender as suas intersecções do mundo do trabalho, considerando a atualidade do capitalismo.

Na sequência, o trabalho apresenta uma análise sobre o desemprego como uma das expressões da condição histórica de subalternidade da classe trabalhadora na ordem do capital e como esta condição se expressa particularmente na vida de jovens vulneráveis socialmente no Brasil atual. Para tanto, o trabalho apresenta uma análise de dados e informações de publicações de órgãos oficiais como do Instituto Brasileiro de Geografia e Estatística - IBGE, dados do Instituto de Pesquisa Econômica Aplicada - IPEA e das Nações Unidas. A análise dos dados e informações são realizadas adotando-se uma análise de base hermenêutica-dialética. (MINAYO, 2001).

Os resultados apontam que o desemprego juvenil, enquanto uma expressão da situação de vulnerabilidade social da juventude brasileira no contexto atual do mundo do trabalho revela, particularmente, uma expressão da condição estrutural de subalternidade da classe trabalhadora no capitalismo contemporâneo.

\section{Juventude, Subalternidade e vulnerabilidade social: expressões atuais do mundo do trabalho}

A construção da definição de juventude é uma tarefa difícil como afirma Dayhell (2003), pois seus constituintes perpassam por critérios históricos e sociais. A juventude deve entendida em uma ampla constituição. Possui questões específicas que marcam a vida de cada sujeito; não se reduzindo apenas a uma ideia de transitoriedade, pois é um processo. Durante a juventude ocorrem mudanças nos campos biológicos, físicos, sociais e relacionais, os quais são vividos de forma intensa. Ainda de acordo com o autor, esse processo recebe influências do contexto social no qual o sujeito está inserido. Assim, o contexto social está intimamente relacionado ao pleno desenvolvimento, ou não, dos potenciais dos jovens (DAYHELL, 2003). Dessa forma, podemos considerar que se do contexto em que o jovem está inserido não provem os mecanismos e recursos necessários para que este desenvolva suas potencialidades, esta condição poderá acarretar um desenvolvimento humano deficitário.

O Estado e a sociedade depositam na juventude suas expectativas quanto ao futuro. Ao fazerem isso partem da ideia de que é da responsabilidade do jovem o desenvolvimento do país. Entretanto, segundo Abramovay (2002), ao contrário desta perspectiva, o jovem enquanto sujeito 
sócio-histórico, encontra-se em estado de insegurança, instabilidade e marginalidade. O jovem, portanto, é um sujeito vulnerável histórico e socialmente. Seja por que dê um lado, grandes expectativas são depositadas socialmente nele, seja por que ainda não possui as condições de desenvolvimento necessárias para ser um sujeito pleno no desenvolvimento de suas potencialidades. A vulnerabilidade, expressa na juventude, quando analisada estruturalmente, pode ser vista ainda como uma expressão da condição de subalternidade de determinados grupos na sociedade.

o conceito de subalternidade tem sido utilizado na contemporaneidade para descrever grupos que estão em condições de exploração ou que não possuem os meios para atingir uma condição de vida plena, como explicitado no entendimento sobre a juventude. De acordo com Simionatto (2009) para que possamos compreender as classes subalternas devemos, primeiramente, abordar as questões de dominação presentes na sociedade. Os grupos dominantes, "[...] escondem, suprimem, cancelam ou marginalizam a história dos subalternos.” (BUTTIGIEG, 1999, p.30 apud SIMIONATTO, 2009, p. 2). Estas medidas se efetivam através de um processo político-cultural de dominação.

Dessa forma, um dos espaços de dominação é o Estado, sendo compreendido como unidade histórica das classes dirigentes. Criado a partir do Estado burguês, de novas ideias sobre direito, política, educação, economia e ética, se constitui numa unidade, não apenas no contexto jurídico-formal, mas ideologicamente projetada para toda a sociedade (SIMIONATTO, 2009). Para Gramsci (2012) tal unidade é resultante das relações entre o Estado e a sociedade civil, sendo que as classes subalternas possuem no seu desenvolvimento histórico um laço com a sociedade civil. Contudo, para que haja a unificação ambas - classes subalternas e sociedade civil - devem se tornar Estado.

Os grupos subalternos estão sujeitos aos grupos dominantes e somente uma vitória permanente é que traria o rompimento da subordinação. Entretanto, não de forma imediata, pois percebe-se na historicidade dos grupos subalternos que mesmo que haja uma aparente vitória, os mesmos permanecem apenas em uma posição de defesa, um estado de alerta (SIMIONATTO, 2009); ou seja, essa condição de subalternidade pode ser superada apenas através da vitória permanente; da conquista da autonomia, como consta a seguir:

A condição de subalternidade só pode ser superada pela conquista da autonomia e isso, para G., pode ocorrer somente por meio de um longo processo e de uma luta complexa. Para que uma luta contra a estrutura de poder existente tenha êxito é necessário, em primeiro lugar, compreender aquilo que a torna flexível e duradoura. (BUTTIIEG in LIGUORI; VOZA, 2017, p. 747).

A forma de vida estatal se concebe de forma dinâmica e processual, onde existe a formação e superação de equilíbrios instáveis a partir dos interesses dos grupos dominantes e os interesses daqueles que estão em subordinação. Assim, podemos perceber que os interesses de ambos estão interligados, implicando-se diante da organização econômica e política presente em cada Estado-nação. E, ainda o Estado consiste em ações teórico-práticas através das quais as classes dominantes exercem sua dominação, mas que também obtém de forma ativa o consenso dos seus governados (SIMIONATTO, 2009).

A categoria de "subalternidade" é relacional; ou seja, não é compreendida como algo inerente às classes subalternas ou ao subalterno, mas que define esses sujeitos a uma relação de poder impostas pelo Estado, na sua íntima relação com a sociedade civil, ou seja, enquanto Estado Ampliado, que oprime, subordina e domina, através da cultura, da ideologia política e econômica. 
Essa relação de poder que produz a falta de oportunidades e escassez de recursos fazendo com os sujeitos em subalternidade não possuam os meios para alcançar uma vida digna.

Outro conceito importante que remete a falta de oportunidade e escassez de recursos é a vulnerabilidade social, sendo um fenômeno que é vivenciado pelos jovens e que se caracteriza como uma destituição dos meios adequados e suficientes para que este sujeito atinja uma vida digna e plena, podendo ser compreendida como:

[...] o resultado negativo da relação entre a disponibilidade dos recursos materiais ou simbólicos dos atores, sejam eles indivíduos ou grupos, e o acesso à estrutura de oportunidades sociais, econômicas, culturais que provêm do Estado, do mercado e da sociedade. Esse resultado se traduz em debilidades ou desvantagens para o desempenho e mobilidade social dos atores (VIGNOLI, 2001; FILGUEIRA, 2001 apud ABRAMOVAY, 2002, p. 10).

Quando discorremos sobre vulnerabilidade social falamos sobre o conjunto de características, habilidades e recursos que devem pertencer a um determinado grupo social, mas que são insuficientes para lidar com as oportunidades que são ofertadas pelo Estado, pelo mercado e pela sociedade, o que promove a dificuldade de ascensão ao estado de bem-estar ou plenitude da vida.

A vulnerabilidade social promove desvantagens e dificuldades no acesso às estruturas de oportunidade, e sua justificação está em “[...] um conjunto de dados secundários sobre a educação, saúde, cultura, lazer e trabalho, insumos fundamentais para o desenvolvimento dos recursos materiais e simbólicos." (ABRAMOVAY, 2002, p. 13). Essa noção indica que as questões deficitárias que envolvem o acesso dos jovens aos bens e serviços de consumo contribuem para a perpetuação da vulnerabilidade social.

A vulnerabilidade social é, portanto, traduzida como debilidades e desvantagens que produzem consequências negativas no desempenho e na mobilidade social dos jovens (VIGNOLI, 2001; FILGUEIRA, 2001 apud ABRAMOVAY, 2002). Mesmo com as evidências dessas dificuldades e desvantagens, no plano ideal, ao jovem é incumbido grandes potencialidades, sujeitos chaves para o desenvolvimento nos mais variados contextos da sociedade, entretanto, no plano real, o que se mostra é contrário a essa incumbência.

Um dos reflexos da vulnerabilidade está relacionada ao trabalho, justamente devido às exigências do mercado e dos novos modos de produção que contribuem para que os jovens enfrentem maiores dificuldades relacionadas a instabilidade empregatícia, ao crescimento do mercado informal, à precarização do trabalho e ao desemprego (ABRAMOVAY, 2009; ALVES, 2017).

Para que possamos compreender as questões que concernem as dificuldades relacionadas ao mercado de trabalho primeiramente temos que situar o contexto-histórico do mundo do trabalho no Brasil. Como discorre Alves (2012), faz-se necessário contextualizar o precário mundo do trabalho no Brasil, que produz uma condição salarial de caráter flexível onde há marcas de redundância e intermitência. (HARVEY, 1992 apud ALVES, 2012).

A partir do século XXI ocorre uma maior amplitude e intensidade das principais determinações da nova condição salarial advindo da nova era do capitalismo no Brasil. Neste período o contexto trabalhista precário em nosso país adquire uma nova forma de existência. Assim, nas últimas décadas o Brasil viveu de expansão e reorganização do capitalismo que impactaram o mercado de trabalho. Devido a essa nova ordem econômica as taxas de desemprego sobem em algumas regiões metropolitanas, inclusive do público jovem, que é o mais afetado pelo desemprego (ALVES, 2012). 
Tais mudanças na estrutura do mundo do trabalho estão relacionadas a um processo histórico, de larga escala, que impulsiona o país na globalização a partir da década de 90 através do neoliberalismo, que modificou suas dimensões após o início do Século XXI. A contínua linha da precarização é marcada pela exploração do desemprego nas regiões metropolitanas como descrito no parágrafo anterior e a reestruturação da produção atingiu o mundo do trabalho no país. Ao longo do fim do sec. XX e a era do neoliberalismo fez com que a reorganização do capitalismo, objetivando novos moldes para a acumulação capitalista, substituindo o desenvolvimento nacional que vinha desde a década de 1970, impacta-se significativamente nas relações de produção. (ALVES, 2012).

Após a virada do milênio, o Brasil vivera uma nova reorganização política, econômica e social, denominada neodesenvolvimentismo, que seria o marco que culminaria para deixar de lado a era neoliberal vivenciada na década anterior. O Estado então desempenhava um novo papel para o mercado, trazendo uma nova perspectiva que visava uma redução das desigualdades e fortalecimento do mercado (MATTOS; PEREIRA, 2016). Os governos do Partido dos Trabalhadores - PT possibilitaram a criação de três vezes mais empregos formais que o governo anterior. Entretanto, houve uma ampliação da flexibilização nas relações de trabalho que resultou em relações instáveis, trazendo maior rotatividade, admissões e desligamentos em postos de trabalho (MATTOS; PEREIRA, 2016).

Houve um crescimento econômico, fortalecimento do mercado, aumento dos empregos, promoção da igualdade quanto ao consumo de bens; e, por outro lado, a implementação de políticas voltadas ao direito dos trabalhadores, culminou em uma desregulação dos modos de trabalho, afetando a proteção social dos trabalhadores, através da terceirização e flexibilização (MATTOS; PEREIRA, 2016). O aumento do poder aquisitivo e a possibilidade de maior consumo, aumento da economia promovendo maior admissão de empregados no trabalho informal produziu transformações positivas, mas que também trouxeram uma precarização e instabilidade em níveis proporcionais. Dessa forma, “[...] ao comprometer-se com a redução das desigualdades, não o faz de forma estrutural, mas com a adoção de políticas compensatórias, que deveriam ser acompanhadas por políticas estruturantes [...]" (MATTOS; PEREIRA, 2016, p. 68), pois são essas que podem solucionar os problemas de desigualdade social e não apenas atenuar os seus efeitos. De tal forma, é possível perceber que no atual contexto do mundo do trabalho as expressões de vulnerabilidade são consequências do processo de restruturação produtiva e de flexibilização das relações de trabalho, associadas à precarização dos direitos do trabalhador, o que confere à classe trabalhadora o reforço de sua condição de subalternidade no capitalismo contemporâneo.

\section{Jovens vulneráveis no Brasil: o desemprego como expressão de subalternidade.}

Nos últimos anos no Brasil, as medidas políticas de redução de danos às condições de vulnerabilidade social da classe trabalhadora, adotadas pelos governos petistas, diante da precarização das relações de trabalho próprias da atual fase do capitalismo contemporâneo (ALVES, 2012) começaram a perder força. (MATTOS; PEREIRA, 2016). Esse enfraquecimento das medidas de proteção e auxílio à classe trabalhadora passou a ser o mote dos que sucederam os petistas no governo. Fundamentados em perspectivas de caráter neoliberal, tais governos empreenderam esforços políticos e jurídicos para reformar as legislações trabalhistas, eliminando o seu caráter protetivo do trabalhador. Essa foi a direção da reforma trabalhista e tem sido a direção da gestão das políticas sociais de modo geral no Brasil recente. (VALENTE; FOGAÇA; SILVA, 2018). Como 
consequência desse processo o que se verifica é o reforço da condição de subalternidade dos diferentes grupos de trabalhadores, que vêm solapadas as oportunidades de trabalho protegido. A tônica do mundo do trabalho, conforme visto em Alves (2012) é a precarização, a flexibilização e a intensificação da informalidade.

Ao projetar as políticas voltadas para a juventude os governos recentes não têm atingido a toda população juvenil, principalmente, quando consideramos a diferenciação feita entre raça e classe: "[...] a juventude a qual nos referimos é aquela que vive nas periferias, jovens negros, pobres, que vivenciam a intensificação das expressões da questão social, o processo desenfreado da criminalização e marginalização da pobreza." (BONALUME; JACINTO, 2019, p. 161). A juventude de modo geral, conforme visto, é um grupo vulnerável, e mais vulneráveis são ainda aqueles pertencentes aos grupos citados pelos autores. No Brasil, as políticas públicas ainda negligenciam as múltiplas vulnerabilidades que assolam o jovem periférico, negro e pobre. A estes sujeitos vulneráveis a face do Estado que mais se apresenta é aquela punitivista. A proteção ao jovem cada vez mais se fragiliza, na medida em que a vulnerabilidade estrutural se acentua. A precarização das relações de trabalho faz com que o jovem vulnerável socialmente perca as parcas condições de promoção humana e social. Diante de um cenário de restrição de oportunidades e vantagens por parte do mercado de trabalho, do Estado e da sociedade, o que cresce são as situações de vulnerabilidade social dos grupos subalternos. A juventude é um dos grupos mais expostos a esse processo, pela sua própria condição de instabilidade, insegurança e marginalidade, quando pertencentes a grupos historicamente estigmatizados, como é o jovem negro e o periférico.

Estes fatores de vulnerabilidade social da juventude, se revelam, do ponto de vista estrutural, como expressões da condição de subalternidade daqueles que, pertencentes à classe trabalhadora, se veem expostos aos contornos da questão social, no contexto do capitalismo contemporâneo. Dessa forma, enquanto parte da população brasileira representativa dos grupos subalternos, os jovens vulneráveis socialmente permanecem estigmatizados socialmente pela criminalização da pobreza, através do apoio promovido pela mídia que fortalece o estereótipo do perfil marginal desses jovens (BONALUME; JACINTO, 2019). Essa realidade socialmente produzida impõe consequências severas para a vida dos diferentes grupos subalternos, cuja expressão é relevante e perversa quando analisamos particularmente as condições de vida de jovens vulneráveis. Sem prescindir da importância da análise dos diferentes fatores que podem compor as situações de vulnerabilidade juvenil, desde o desemprego ao encarceramento em massa dos jovens que compõem o exército industrial de reserva; e, encontram-se sem perspectivas social e econômica dentro da sociedade capitalista, podemos destacar a exclusão que perpassa a vida dos jovens brasileiros, enfocando questões como abandono escolar e baixa empregabilidade juvenil, gerada a partir desse quadro de precarização estrutural do mundo e das relações de trabalho, determina a condição de desemprego juvenil. Conforme dados do Instituto Brasileiro de Geografia e Estatística - IBGE apud Neto (2018) no ano de 2017, 21,7\% dos jovens de 15 a 29 anos não estudavam nem trabalhavam; em 2016, o percentual foi de 20,5\%; ou seja, uma diminuição não significativa, o que indica a manutenção do problema. Estas questões, segundo os mesmos dados, se acentuam para jovens mulheres. A incidência para elas é de $27,1 \%$ ao passo que para os homens foi de $16,4 \%$.

Esses números, não somente representam o desalento da população, diante de um cenário de retrocessos no mundo do trabalho, seja devido ao retrocesso nas políticas protetivas, seja por que o próprio mundo do trabalho se reorganiza constantemente para forjar meios para a sua precarização e flexibilização. Assim, aquela parcela da população mais vulnerável fica à mercê das flutuações do mercado, sofrendo mais imediatamente com ela. A tendência é o jovem vulnerável 
aceitar com maior facilidade as condições precárias de trabalho e de vida como saídas inseguras para a busca de sua sobrevivência, por falta de outras opções. Nesse caso, vê-se a restrição de oportunidades, como condição objetiva para a piora do quadro de vulnerabilidade social juvenil. Como exposto por Bonalume e Jacinto (2019, p. 162):

Essa lógica sustenta a estrutura do capital e se propaga por todas as esferas da vida social, sobretudo da classe trabalhadora que é forjada a vender a sua força de trabalho como forma de garantir o mínimo para a sobrevivência. Para isso, além de polivalente, precisa submeter-se à exploração e precarização das relações de trabalho, o que inclui a ampliação da jornada, redução de postos, funções repetitivas e mecanizadas em troca de um salário irrisório.

Deste modo, esse processo mantém inerte as classes subalternas, que na sua condição de incapaz de reverter o quadro de opressão, têm perdido cada vez mais os avanços sociais, políticos e jurídicos que alcançara em conjunturas anteriores, posto que conforme aponta Buttigieg (2017) somente a autonomia gerada por uma vitória permanente pode garantir a superação a condição de subalternidade. Doutra forma, os avanços são sempre parciais e instáveis. A perpetuação das situações de vulnerabilidade dos grupos que não atingem postos de trabalho ou nível de ensino capaz de elevar suas possibilidades e perspectivas demarcam a manutenção da condição estrutural de subalternidade da classe trabalhadora no mundo do trabalho neste contexto do capitalismo contemporâneo. A precarização das condições de trabalho e a precarização de suas relações são expressões contemporâneas da condição histórica de subalternidade dos trabalhadores diante da ordem do capital. (ALVES, 2012). A expectativa da população de modo geral no Brasil, em relação ao mercado de trabalho não é boa, considerando que o primeiro semestre de 2019 bateu o recorde no índice de desemprego desde 2012. Segundo dados da Pesquisa Nacional por Amostragem Domiciliar - PNAD (2019) a desocupação chegou a 12,4\%, contra 11,6\% no último trimestre de 2018, enquanto a subutilização da força de trabalho chegou a 24,6\% (BRASIL, AGÊNCIA NOTÍCIAS IBGE, 2019). Inegavelmente a população mais jovem, por se encontrar em idade ativa é a que mais sofre as consequências desses fatores sociais.

A situação menos favorável dos jovens no mercado de trabalho é ratificada pelos microdados de transição. Embora, no quarto trimestre de 2018, a parcela de desocupados com idade entre 18 e 24 anos que conseguiram uma ocupação tenha se mantido estável, enquanto a proporção dos ocupados que transitaram para o desemprego tenha recuado ligeiramente, essa parcela da população ainda é a que possui a menor probabilidade de ser contratada, além de ter a maior chance de ser demitida (LAMEIRAS; CARVALHO; CORSEUIL, 2019, p. 6).

Observando-se ainda que o número de jovens desempregados entre 18 e 24 anos no quarto trimestre de 2018 era de $25,2 \%$, contra $28,1 \%$ no primeiro trimestre do mesmo ano; caindo para $10,7 \%$ entre a população de 25 a 39 anos, no último trimestre de 2018. Portanto, verificamos que a população juvenil apresenta índices mais elevados de desemprego em relação ao restante da população (LAMEIRAS; CARVALHO; CORSEUIL, 2019).

É necessário então, considerar que paralelo à queda das taxas de desocupação, proporcionalmente os índices de vulnerabilidade juvenil à violência crescem, como apresentado no Índice de vulnerabilidade Juvenil à Violência 2017 (BRASIL, 2017). Segundo a qual é possível visualizar o comparativo no qual: 0,33 dos jovens que residem nos locais entrevistados estão inseridos de 
forma precária no mercado de trabalho, significando o mesmo valor se atribui ao índice de homicídio entre jovens de 19 a 24 anos e 25 a 29 anos, analisados separadamente.

Como observado, dados como este deveriam resultar em implementação de políticas públicas que trouxessem resultados efetivos em relação as desigualdades sociais que acometem a população brasileira e geram estagnação das gerações populacionais, que em maioria não encontram meios de subverter o sistema que a mantem em sua condição de subalternidade. Mas ao contrário disto, tem-se como resposta do Estado o fortalecimento de medidas coercitivas, como forma de manutenção da ordem pública. Levando em conta que:

Essa política de criminalização da pobreza e gestão da miséria gerenciada pela lógica do Estado Penal se dá em duas modalidades. O primeiro componente do Estado Penal refere-se à transformação das políticas sociais em instrumentos de controle e vigilância, sobretudo da população pobre e considerada como perigosa. O segundo componente é o encarceramento ou a repressão ofensiva sobre essa mesma população, que atinge prioritariamente negros e jovens moradores da periferia (WACQUANT, 2001 apud BONALUME; JACINTO, 2019, p. 163).

Não sendo suficiente cercear os meios de sobrevivência é necessário criar-se também um monstro a ser combatido. Dessa forma o encarceramento e repressão tornam-se parte importante do processo em tornar a população vulnerabilizada cada vez mais vulnerável, de modo a manter a sua condição de subalternidade diante da ordem do capital.

Desse modo, o controle social legitimado por essa via possui como pano de fundo a propagação de um ideário burguês que responsabiliza, sobretudo, a classe trabalhadora, pela precária condição de vida, pela exploração do trabalho e até mesmo pela intensificação da violência, o que justificaria o ostensivo avanço da ampliação indiscriminada da intervenção penal. (BONALUME; JACINTO, 2019, p. 163)

Perceba-se dessa forma que não significa tão somente a não garantia de direitos sociais, mas sim de todo um contexto estrutural que visa manter a subalternidade enquanto expressão do cotidiano da vida da classe trabalhadora, seja por que a expõe ao desemprego, seja por que a criminaliza a pobreza e com isso sofre mais o jovem desempregado, pobre, negro e periférico. Mantém-se, portanto, a juventude vulnerável socialmente, como uma expressão da condição de subalternidade da classe trabalhadora diante do capital.

\section{Considerações finais}

Diante do que foi exposto neste artigo é possível notar que as condições de subalternidade e vulnerabilidade social da população juvenil, ainda mais os jovens que vivem nas periferias, negros, pobres e que sofrem processos de criminalização e marginalização pelas condições sociais que vivem, promovem consequências negativas, com repercussões para o mundo do trabalho. A proteção destes jovens é cada vez mais fragilizada o que gera a acentuação da vulnerabilidade. A falta de oportunidades e acesso a recursos faz com que estes jovens permaneçam na condição de subalternos.

Como pudemos perceber, a expansão e reorganização do capitalismo promoveu um impacto negativo no mercado de trabalho, onde esta nova ordem econômica aumentou as taxas de desemprego e o público jovem é o mais afetado por essa reestruturação do capital. Dessa forma, 
diante do atual contexto do mercado de trabalho a vulnerabilidade é a consequência negativa das reestruturações de produção, da flexibilidade das relações de trabalho, bem como a precarização dos direitos do trabalhador, reforçando a condição de subalternidade desta parcela da classe trabalhadora, frente a reorganização do capitalismo na contemporaneidade.

De acordo com os dados analisados pode-se evidenciar que a população juvenil apresenta índices mais elevados do restante da população diante do desemprego, e quando essa parcela da classe trabalhadora se insere no mercado de trabalho fica a mercê da precariedade para manter os meios de sua sobrevivência, justamente pela restrição das oportunidades, o que gera consequências ainda mais negativas. Essas condições pioram o quadro de vulnerabilidade, o que determina a manutenção desta parcela de jovens pertencentes à classe trabalhadora na subalternidade, seja pelo retrocesso nas políticas públicas de proteção ou pela precarização e flexibilização promovida pela constante reorganização que o mundo do trabalho sofre atualmente.

A objetivação da piora no quadro de vulnerabilidade social da juventude e a precarização e flexibilização do mercado de trabalho promovem a manutenção da condição de subalternidade, onde os jovens trabalhadores permanecem vulneráveis e, portanto, incapazes de reverter o quadro opressivo, pois o contexto estrutural não garante a sua proteção, não possibilita o acesso a recursos que fariam com que a juventude alcançasse a plenitude e ainda o criminaliza e o marginaliza. Aliado aos processos de restruturação do capital, a ausência da proteção do Estado brasileiro faz com que o desemprego juvenil no Brasil seja uma das expressões da condição de subalternidade da classe trabalhadora, no atual contexto do capitalismo contemporâneo.

\section{Referências}

ABRAMOVAY, Miriam; CASTRO, Mary Garcia; PINHEIRO, Leonardo de Castro; et al. Juventude, violência e vulnerabilidade social na América Latina: desafios para políticas públicas. Brasília: UNESCO, 2002.

ALVES, Giovani. A derrelição de Ícaro: sonhos, expectativas e aspirações de jovens empregados do novo (e precário) mundo do trabalho no Brasil (2003-2013). In: 36º Encontro Anual da ANPOCS - Portal das Ciências Sociais Brasileiras, 2012. Anais (on-line). Disponível em: encurtador.com.br/lCTW7. Acesso em: 21 abr. 2019.

BONALUME, Bruna Carolina; JACINTO, Adriana Giaqueto. Encarceramento juvenil: o legado histórico de seletividade e criminalização da pobreza. In: Katálysis, Florianópolis, v. 22, n. 1, p.160-170, 2019. Trimestral.

BRASIL. Casa Civil. Lei no $\mathbf{1 1 6 4 8}$, de 05 de agosto de 2013. Institui o Estatuto da Juventude e dispõe sobre os direitos dos jovens, os princípios e diretrizes das políticas públicas de juventude e o Sistema Nacional de Juventude - SINAJUVE. Dísponível em: <http://www.planalto.gov.br/ccivil_03/_ato20112014/2013/lei/l12852.htm>. Acesso em 15 mai 2019.

BRASIL. Presidência da República. Secretaria de Governo. Índice de vulnerabilidade juvenil à violência 2017: desigualdade racial, municípios com mais de 100 mil habitantes / Secretaria de Governo da Presidência da República, Secretaria Nacional de Juventude e Fórum Brasileiro de Segurança Pública. São Paulo: Fórum Brasileiro de Segurança Pública, 2017. 87 p.

BUTTIGIEG, Joseph A. Subalterno/Subalternos. In: LIGUORI, Guido; VOZA, Pasquale (Orgs.). Dicionário gramsciano (1926-1937). - 1. ed. - São Paulo: Boitempo, 2017. 
DAL BELLO, Marília Gonçalves. Jovens, vulnerabilidade e violência: outra história é possível?. 2004. 141f. Dissertação (Mestrado em Serviço Social e Política Social) - Universidade Estadual de Londrina, Londrina, 2004.

DAYHELL, Juarez. O jovem como sujeito social. Revista Brasileira de Educação. n. 24. p. 40-52. set-dez, 2003.

Gramsci, A. (2012). Cadernos do Cárcere: Maquiavel, notas sobre o Estado e a Política. v. 3. Rio de Janeiro: Civilização Brasileira, 2012.

LAMEIRAS, Maria Andreia Parente; CARVALHO, Sandro Sacchet de; CORSEUIL, Carlos Henrique L. Seção VIII: Mercado de trabalho. In: Carta de Conjuntura. IPEA: 2019, n 142, 24 p. Disponível em: <http:// www.ipea.gov.br/portal/images/stories/PDFs/conjuntura/190320_cc_42_mercado_de_trabalho.pdf>. Acesso em: 07 mai. 2019.

MATTOS, Fernanda G.; PEREIRA, Juliana N. Neodesenvolvimentismo, informalidade e nova morfologia do trabalho: reflexões sobre a precarização do trabalho no Brasil. Áskesis. v. 12. n. 1. p. 59-72. Jan./Jun., 2016.

MINAYO, Maria Cecília de Souza (org.). Pesquisa Social: Teoria, método e criatividade. 18 ed. Petrópolis: Vozes, 2001.

NETO, João. Mais de 25 milhões de jovens não estudavam em 2017. In: Agência IBGE - Notícias: PNAD Contínua. Estatísticas Sociais: 18 Mai 2018. Disponível em: <https://agenciadenoticias.ibge.gov. br/agencia-noticias/2012-agencia-de-noticias/noticias/21256-mais-de-25-milhoes-de-jovens-naoestudavam-em-2017>. Acesso em: 06, mai. 2019.

PAPALIA, Diane E.; OLDS, Sally Wendkos; FELDMAN, Ruth Duskin. Desenvolvimento Humano. 10. ed. Porto Alegre: AMGH, 2010.

PNAD Contínua: taxa de desocupação é de 12,4\% e subutilização é de $24,6 \%$ no trimestre encerrado em fevereiro de 2019. In: Agência IBGE Notícias. Estatísticas Sociais: 29 Mar 2019. Disponível em: <encurtador.com.br/rtQS6>. Acesso em: 06, mai. 2019.

SIMIONATTO, Ivete. Classes Subalternas, luta de classes e hegemonia: uma abordagem gramsciana. Revista Katálysis. v. 12, N.1, p. 41-49. Jan./jun., 2009. 